\title{
Partnering Accounting and Excel
}

\author{
Mary Janis Rose \\ Cleveland State University \\ Daniel A. Kaminsky \\ Cleveland State University \\ Heidi Hylton Meier \\ Cleveland State University
}

We incorporated the Microsoft Office Specialist (MOS) Excel 2016 Certification Exam into our introductory managerial accounting class at Cleveland State University. The purpose was to increase student engagement, to show how Excel is used in day-to-day business applications, to stress the importance of technology skills in real life business environments, and to improve the relevance of this introductory accounting course for all business majors. This paper describes our experimental study which utilized the Certiport examination process, materials developed and provided to students to assist them to prepare for and be successful on the exam, and the results and feedback that we received from our students. Our analysis allowed us to evaluate our initial course work requirements and plan for an improved syllabus for the Fall of 2021. Even though we were hindered by COVID-19 restrictions, we were able to gather valuable data to share with our University.

Keywords: accounting education, Microsoft office specialist certification, MOS excel skills, technology in business classes

\section{INTRODUCTION}

Results of our Assurance of Learning (AOL) efforts highlighted the need for additional technology skills, specifically Excel, for accounting majors. Faculty feedback, Advisory Board input and accounting students expressed a need for additional training/exposure to Excel. Accounting educators know the importance of Excel skills for accounting students, but we learned that all business disciplines require the use of Excel and other Microsoft Office products to be productive and provide value to employers. Since the Introductory Managerial class is required of all business majors, we felt that the placement of mandatory Excel assignments in this class would be of the most value to business majors. In our first semester, we decided to have the MOS Excel 2016 Certification Exam be a mandatory requirement of the student's final grade; the exam represented $10 \%$ of their final grade. Overall, Excel assignments pertaining to Managerial Accounting represented about $30 \%$ of their overall grade. Both of these illustrate that we immersed the students in Excel training throughout the course. Due to Covid-19, our plans of in-person computer labs each week was severely limited. We were only able to hold in-person labs with $50 \%$ capacity, which meant 
our one-on-one instruction with the students was cut in half. As the semester progressed and Covid-19 was not slowing down, we modified the syllabus of the class and made MOS Certification optional.

In our research, we found that many colleges and universities either require the Certification as part of their curriculum or provide access to students who want to take the Exam. For example, Seattle University's Albers School of Business and Economics as of September 2019 will require new candidates to pass the Certification Exam as part of their graduation requirements. Other schools, such as University of North Carolina's Bryan School of Business and Economics (Greensboro) and Troy University's Sorrell College of Business strongly urge their students to take MOS (Microsoft Office Specialist) Certification exams and provide extensive resources to assist students in preparing for the exam. Those business schools accredited through AACSB (Association to Advance Collegiate Schools of Business) will be looking at expanded accreditation requirements for the incorporation of technology in the classroom. Dr. John Elliott, AACSB Chair (2019-2020) has stated that AACSB schools must quickly adopt technology components in various business courses to better prepare students for the jobs of the future. He urges member institutions to be nimble, connect with corporate leaders, and monitor changing disruptive technologies that impact businesses not only in the United States but around the world. He also encouraged universities to develop continuing education for older workers, especially in technology (Elliott, 2020). We have seen studies that show that workers with MOS Certifications have higher salaries than those that do not have the certifications, for example see www.ziprecruiter.com. Studies show that $67 \%$ of all middle management job openings require a minimum proficiency in technology such as MOS and pay $13 \%$ more than those job offerings that do not require these proficiencies (Burning Glass Technologies, 2015). Employers are looking for students trained in Excel functions such as data sorting, data filters, Vlookups, data validation, and charting to name a few (One Education). Our challenge in this project was to find the right way to deliver the material, engage our students, and prepare them to be successful on the Certification Exam.

\section{LITERATURE REVIEW}

Bakir et al (2019) addressed the certifying of business students in Microsoft Office Specialist (MOS) Certification, specifically Excel. The importance of technological literacy to compete in today's economy is the driving force behind this initiative. The information economy requires all business disciplines to understand how to use the overwhelming amount of data to make strategic business decisions sometimes within a short time frame. The incorporation of MOS Certification in existing classes was in part to comply with directives of AACSB initiatives to increase technology into the classroom. AACSB states that "technology in business curricula is near a necessity" and "graduates need to have the ability to leverage technology in a scalable fashion to advance firms' strategies and operations" (AACSB, 2002, p. 11). They indicated that their research showed that all business disciplines require basic to advanced skills in MOS software and other analytical software programs. This paper describes how MOS certification is incorporated within the class coursework in introductory IT (Information Technology) classes. They used GMetrix as part of the study materials necessary to study for the MOS Excel exam and for the IT portion, they used MyEducator. MyEducator is an online textbook with interactive lessons and modules on Microsoft Excel and Access. Their pilot class in the Fall of 2017 without GMetrix showed a pass rate of $61 \%$. In the Spring of 2018, they expanded their study to four classes and added GMetrix into the coursework. The pass rates increased to $71 \%$ in the business IT class and to $66 \%$ in the MIS class. One of the major concerns regarding continuing the program was the added costs of MOS certification and GMetrix to the students.

Rebele et al (2019) addressed the issue of the importance of "soft skills" and technical knowledge being included in accounting undergraduate programs. The article highlights the need for these skills to be part of a four-year degree program, but cautions that over emphasis of these objectives in accounting curriculum may impede the main objectives of the accounting curriculum. The accounting curriculum must include necessary accounting competence required by employers when students graduate. This article focuses most of its attention on critical thinking, ethics, and communications skills and the "soft skills" required after graduation. The accounting profession has outlined a laundry list of "soft skills" that should be taught in 
accounting programs, but little advice is offered on how these skills could be taught without sacrificing some of the technical accounting proficiency skills required of the students. They indicated that most universities limit the hours allowed for majors, thus limiting the contact hours and number of courses to teach the required skill sets for a major. The public accounting profession instituted a 150 -hour requirement to be a CPA, but did little to require the profession to use these additional hours to require students to take courses that would enhance "soft skills" and computer software skills. They imply that the profession missed an opportunity to increase these technical skills with future employees within the accounting profession. They further state that the 150-hour rule only applied to students pursuing public accounting, thus leaving out a large population of students pursuing private accounting. The next major issue addressed is whether accounting faculty had the competency to teach "soft skills" and computer software skills.

Rotondo (2020) addressed the deficiencies in technology skills of accounting students. The paper points to the 2012 Pathways Commission report that addressed the technology curriculum deficit and when the Technology Task Force of the Pathways Commission did further studies in 2015, came up with a list of 25 technologies that accounting students should know. The number one ranked technology was electronic spreadsheets like Excel. Their research showed that Excel skills are the most common skill required of entry-level accountants. A survey by Rassuli, et al. (2012) of top 50 Midwestern employers showed that Microsoft Excel and Microsoft Word were the highest-ranking IT skills required of undergraduates for employment opportunities with these companies. A survey done by Pelzer et al (2018) of recent accounting graduates regarding workforce preparedness showed that the lack of Excel skills was their biggest shortcoming in their new jobs. His article showed that students used GMetrix, Udemy and YouTube as study guides for their Excel exam preparations. His results for one semester of 29 students accomplished a $90 \%$ pass rate. This was not a new class or a modified accounting class but was the department of accounting promoting the exam to existing accounting students during the semester. The department's emphasis was that they would promote the necessity of Excel skills and make it the responsibility of the students to take advantage of the opportunity to take the exam at their Certiport Authorized Testing Center (CATC) in the College of Business. They sold students vouchers to take the exam.

Lee et al (2019) addressed the technical issues of using Excel shortcuts to create meaningful worksheets that show data useful for decision making. As explained in the article, there are often several ways to code the correct solution within Excel. The emphasis in this article is engaged learning skills of the instructor and students. They use a game-based approach to encourage students to actively learn the materials within a fun and challenging game setting including a Jeopardy!-style game that focused on the Excel shortcuts. The Jeopardy!-style game can be played with three people or three teams of students. The game can be downloaded and shown on a large screen in the classroom. The game allows the instructor to edit the categories worksheet and add additional new shortcuts developed since the game was created. In addition, they used "The Periodic Table of Excel Shortcuts and Functions (Windows based) to assist students in learning various Excel shortcuts and functions. The table was adapted from Data Pig Technologies (2013).

Baldwin Wallace University, a private liberal-arts-based college in Berea, Ohio, recognized the importance of technology certification, so they created a 3-credit hour course offering both Bloomberg and Excel Certifications. ACC 245 is a required foundation course for accounting and finance majors. The course requires a $\$ 30$ fee for "Acct Excel Certifications" in addition to the tuition and fees for the course. From their catalog description, it is unclear where and when students take the certification exams.

Baldwin Wallace also recognized that training is required to "take your career to the next level" and offers Microsoft Office Specialist Expert in Excel 2019 as part of their career training offerings. This course is completely online and costs $\$ 650$ which includes a testing voucher, good for 6 months. It is unclear where and when students take the certification exams but the course is self-paced and open enrollment so testing is completed individually. There are no prerequisites, but the requirements are: PC (Macs are not compatible), Windows 10 or later, the latest version of Google Chrome or Mozilla Firefox, and Microsoft Excel 2019 and Adobe Acrobat Reader resident on the student's PC. 


\section{IMPLEMENTATION}

We began the program in the Fall of 2020 after receiving a grant through the Teaching Excellence Award Program from the Provost of our University. As stated earlier, our goal was to encourage students to study and successfully complete the MOS 2016 Excel Certification Exam. Our first priority was to adjust the syllabus for ACT 222 to cover various Excel topics and the Certification Exam. We reviewed the McGraw-Hill Connect (on line learning portal) assignments from our existing text, Financial \& Managerial Accounting Information for Decisions $8^{\text {th }}$ edition, (Wild, et al.) that pertain to Excel functions as well as Excel problems from Pearson to accomplish two objectives: first, to highlight course learning objectives and second, to teach new Excel functions. We incorporated ten assignments into the Fall 2020 semester curriculum. Two of the assignments were major Excel projects worth 100 points each and included the managerial topic ABC (Activity Based Costing) costing and from financial accounting, charting financial statement data into charts and graphs.

Our next major task was to contact Certiport (authorized Microsoft testing entity) to obtain cost data and system requirements for Cleveland State University (CSU) to be a Certiport authorized testing center (CATC) and to purchase licenses. We estimated that over the year we were going to have between 400 to 500 students take the exam. The testing fees could not be added as a lab fee since the State of Ohio and CSU froze any increases in tuition. We were able to obtain funding for this cost through our Department's office. With the contract approved and the funding in place, the next step was to coordinate with the business college IT manager and Certiport to download the testing software (Compass) on the computers in one of our labs. MOS allows two levels of certification: Specialist, and Specialist Expert. We choose the Specialist certification because our students were in their first or second year of school and we assumed that their knowledge level of Excel was either limited or moderate. Entry level certification is a "vehicle to provide students with viable skills needed by the workforce" (Randall and Zirkle. 2005, p. 287). "These certifications also prepare students to compete in competitive job markets and showcase their marketability while they are still in school" (Bakir, et. al., ISCAP 2019). The 2016 MOS Excel Specialist exam was chosen because the current software in our labs is the 2016 Microsoft Office Suite.

With Covid-19 limitations that affected all teaching at the University in the Fall of 2020, we were able to safely conduct $50 \%$ of the in-class labs for Excel training. Towards the end of Fall 2020 we modified the mandatory MOS Exam requirement to optional since the University closed in-person classes after Thanksgiving. We were able to get an exemption from the Provost's office to conduct the Certification Exams under strict Covid-19 provisions. Eleven students chose to take the exam and five passed. The pass rate was $45.45 \%$, which is below the national average of $63 \%$ shown by Certiport. These results were not what we had expected or hoped for, but under the current teaching restrictions, were not surprised by these results.

The lessons learned from this first session showed shortcomings in our Excel content delivery method, additional resources for students were needed, and marketing of the value of the Certification Exam was essential. With this self-analysis completed, we restructured the course for the Spring 2021 term.

We expanded the Excel assignments in Connect to sixteen and included more class time to teach various Excel functions that were covered on the Excel exam. Our Graduate Assistants (GAs) established a tutoring schedule just for Excel so that students could go to a Zoom meeting for one-on-one or group help. Because our first attempt at evaluating this certification was thwarted by the pandemic, we expanded the MOS Exam availability to one Managerial graduate course (ACT 600), which made it a mandatory project and Beta Alpha Psi (BAP), an honorary fraternity, for all current and past members on an optional basis.

Feedback from students from the Fall term indicated that more resources were needed so that students could prepare for the Exam and not have to rely solely on in-class or Zoom meetings from the instructors or GAs. The GAs created a Blackboard course for the 2016 MOS Excel Certification Exam following the book MOS 2016 Study Guide (Lambert, 2017) which is available through our library as an online text. The text includes downloadable Excel files that the GAs worked, then recorded solution videos and posted the videos in the Blackboard course to explain how-to-do it. 
They also included videos describing how to register in Certiport, how to access the eBook from our library, how to schedule the Exams from Home (EFH), and what to expect when taking the Excel Certification Exam to name a few. This Blackboard "course" was available in early February 2021 and was copied to two instructors' managerial Blackboard courses and the graduate class mentioned above. Feedback from Spring semester students was positive about how well the site was organized and helped them succeed on the exam. This Excel Certification course in Blackboard is also directly used by adding BAP students to the course since they are no longer enrolled in managerial accounting courses. Some of the folders in this Blackboard site are shown in Figure 1.

\section{FIGURE 1 \\ BLACKBOARD SITE FOLDERS}

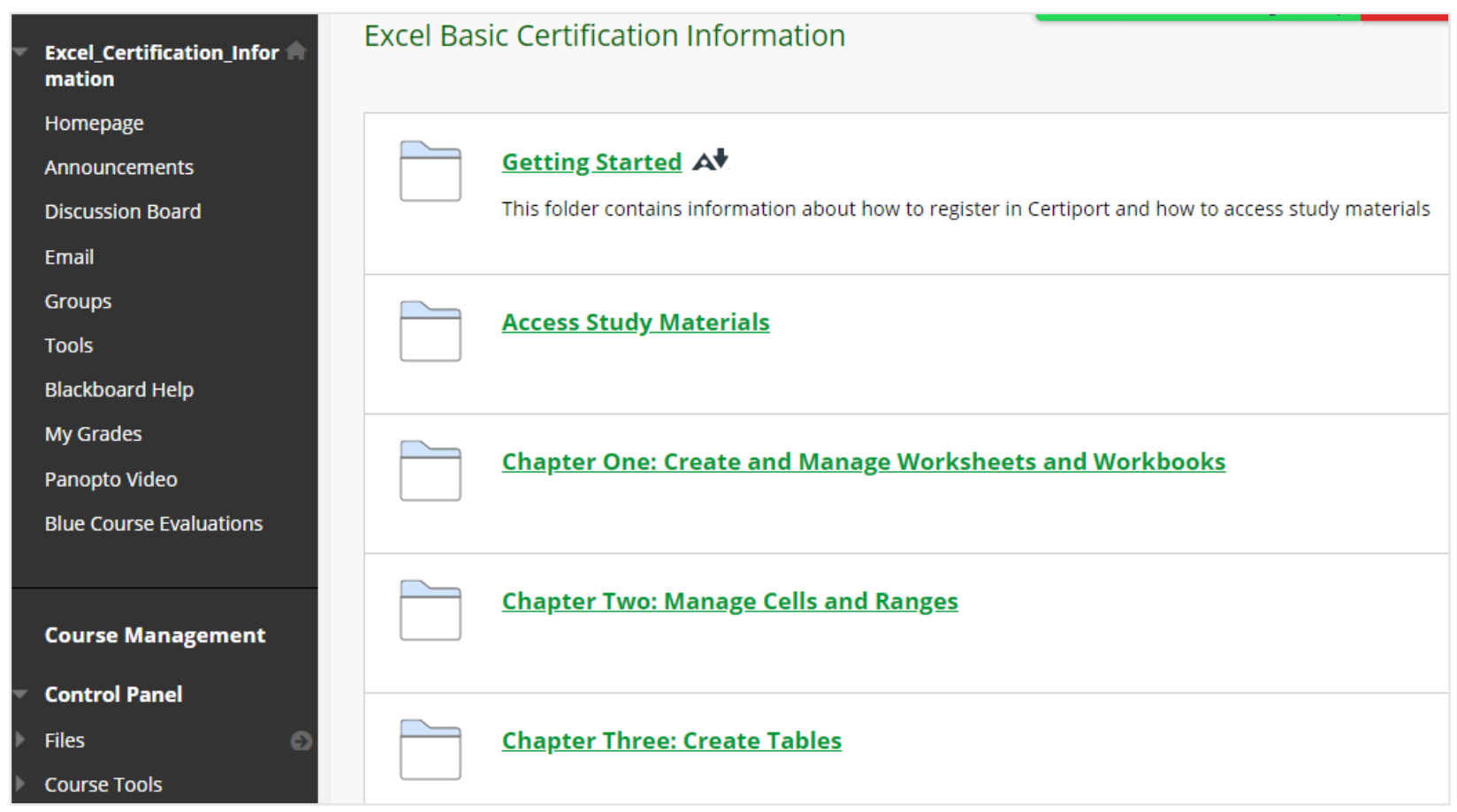

Promoting the Certification Exam was done via classroom discussions, the Monte Ahuja College of Business newsletter, Infographics, and frequent online postings to student emails and Blackboard. Some examples of these promotions are shown in Figures 2 and 3 in the appendix.

\section{OVERALL RESULTS FOR SPRING 2021}

The results are divided into two groups. The first group (Table 1) only contains the undergraduate Managerial Accounting ACT 222 students. Group two (Table 2) includes all students who took the exam in Spring of 2021. Covid-19 put severe constraints on our study, but it did allow us to work out delivery issues for our Spring 2021 classes. In the Spring, we had either fully online classes or limited class sizes for in person instruction. The on-campus class required the MOS Excel 2016 Certification Exam as a key semester grade component. The online classes were encouraged to take the Exam with a passing score on the MOS exam replacing the $3^{\text {rd }}$ managerial exam. The results for Spring 2021 are as follows in Table 1. 
TABLE 1

SPRING 2021 EXAMINATION RESULTS FOR ACT 222 STUDENTS

\begin{tabular}{|c|c|c|c|c|c|c|}
\hline OPTIONAL ACT 222 sections & Pass & Fail & REQUIRED ACT 222 section & Pass & Fail & \\
\hline Accounting & 9 & 2 & $\overline{\text { Accounting }}$ & 2 & 2 & \\
\hline Finance & 6 & 2 & Finance & 1 & 5 & \\
\hline General Business & 0 & 2 & General Business & & 6 & \\
\hline Information Systems & 2 & 2 & Information Systems & & 0 & \\
\hline International Business & 0 & 5 & International Business & & 0 & \\
\hline Marketing & 7 & 3 & Marketing & & 1 & \\
\hline Management & 1 & 2 & Management & & 1 & \\
\hline non-business & 1 & 1 & non-business & & 0 & \\
\hline \multirow[t]{2}{*}{ Operations \& Supply Chain } & 0 & 2 & Operations \& Supply Chain & 1 & 0 & \\
\hline & & & Business Economics & & $\underline{3}$ & \\
\hline Total & 26 & 21 & Total & 4 & 18 & 69 \\
\hline
\end{tabular}

As seen in Table 1, 69 ACT 222 students took the exam, and thirty students passed the exam for a $43.48 \%$ pass rate. This is similar to the results in Fall of 2020 but still significantly below the national average pass rate of $63 \%$. Bakir et al conducted a similar study by including MOS Certification as a component in several of their introductory courses in MIS. Their students had pass rates of 61 to $71 \%$ over the two semesters that they gathered data. Their results were impressive. Some of the differences between our two studies were that they conducted the study in 2017 and 2018 prior to Covid-19 restrictions. Second, the class was an IT introductory class that focused on Microsoft Office software and MIS general topics, whereas our class had other required objectives for managerial accounting in addition to the Excel component. Third, the last three weeks of the IT class were a concentration on MOS Excel Certification Exam requirements with one-on-one instruction on Excel functions. We had some lab work and Zoom meetings with students and with graduate tutors online. The rest was a self-study through our Blackboard course on Excel. Lastly, the students used GMetrix software and the MyEducator e-book to assist them with exam preparation in the last three weeks of their class. This article gave us some great insights on how we will teach our ACT 222/MOS Certification classes in the future (Bakir et al)

In Table 2, we included all students in Spring 2021 who took the exam. This group included graduate students as well as members of Beta Alpha Psi. A total of 109 students took the exam and 52 passed for a pass rate of $47.71 \%$. This pass rate was much better than for just the ACT 222 students, perhaps because the students were farther along in their academic careers and took it more seriously. 
TABLE 2

EXAMINATION RESULTS FOR ALL STUDENTS

\begin{tabular}{|l|l|c|c|c|c|c|}
\hline Semester & Course & $\begin{array}{c}\text { MOS Required or } \\
\text { Optional }\end{array}$ & Total students & \# taking exam & pass & fail \\
\hline Fall 2020 & ACT 222 & Required, then optional & 22 & 11 & 5 & 6 \\
\hline Spring 2021 & ACT 600 & Required project & 20 & 20 & 9 & 11 \\
\hline Spring 2021 & ACT 222 & $\begin{array}{c}\text { Optional; passing score do } \\
\text { not need to take the final }\end{array}$ & 127 & 47 & 26 & 21 \\
\hline Spring 2021 & ACT 222 & Required component & 24 & 22 & 4 & 18 \\
\hline Spring 2021 & BAP & Optional & & 9 & 8 & 1 \\
\hline Summer 2021 & ACT 600 & Required project & 34 & 30 & 30 & 0 \\
\hline & & Intro Managerial \\
& & Accounting & & & & \\
\hline & & $\begin{array}{c}\text { MBA Managerial } \\
\text { Accounting }\end{array}$ & & & & \\
\hline & Beta Alpha Psi & & & & \\
\hline
\end{tabular}

\section{LESSONS LEARNED}

Never start a pilot program during a global pandemic!! Never assume that students have an understanding of technology issues even though they use technology every day of their lives. We assumed that students had Excel training in our IST 203 (Software Tools for Personal Productivity) or in high school. We learned that students either did not have the basic Excel training or remembered little if they did. In addition to Excel training, knowledge of the structure of the Excel Certification Exam is another hurdle that we did not realize would be so important for success.

We learned that it was critical for success to reinforce the concept that businesses use Microsoft software and other software products to achieve efficiencies and understanding of the data flowing through the enterprise systems. Getting students to understand the lifelong need for these skills at the very beginning of the semester will help them to "buy into" the overall reason for Excel Certification in the class. We concluded that a lot of CSU students did not even know that they could obtain (free of charge!) Microsoft Office Suite software from the University and that many of the students did not have the software loaded on their laptops or Macs.

The overall costs to the University were much higher than we expected. We were able to obtain funding for 500 licenses at a cost of $\$ 4,680$ for one year. (Individual licenses purchased directly from Certiport range from $\$ 75-\$ 100$ ). Future funding of licenses is a major issue that will have to be addressed in the very near future if this program is to continue beginning in the Spring 2022 semester.

Technology issues were encountered during the exam. Some of the issues were related to Certiport software and were resolved by Certiport. Other issues were connectivity issues and hardware problems of the lab computers. Most of these issues were addressed by IT personnel who were available during our testing days. The Compass software from Certiport that allows the student to take the exam is tied to the version of Microsoft Office; in our labs it is currently 2016. This means that only MOS 2016 exams can be administered in the lab.

The optional ACT 222 students and the graduate and BAP students were in remote status because of the pandemic. We learned that Exams from Home (EFH) was available through Certiport. They increased the number of links to accommodate the world-wide move to online testing, so we were able to deliver most of our exams via EFH. While this worked well overall, the entire process of obtaining the links from Certiport, scheduling the students in blocks of ten, and then proctoring the exam itself takes a large amount of administrative time. 


\section{CONCLUSIONS}

Our major objectives with introducing Excel into the classroom were to increase engagement, to show how Excel is used in a business setting, to show how technology skills are important in a business environment, and to improve the relevance of introductory managerial accounting for all business majors. We have concluded that we were somewhat-to-very-successful in achieving these objectives. Feedback from class surveys indicated that $71 \%$ of the respondents felt that adding MOS Certification made the class more relatable to "real life." A marketing major who passed the test stated, "I really love when classes incorporate Excel. My business statistics class does this as well. I find this extremely helpful as my career will use Excel. I have learned so many new things in Excel this year." A management major who couldn't take the exam due to a full class and job load commented "This class prepared me for a real-life business setting. I interned at a marketing agency and the main software they used was Excel" In an exit survey, the response to the question "Were your Excel skills enhanced by the Excel component in this class?" showed that $64 \%$ of the students answered that the Excel component was either somewhat or extremely helpful. Eighty percent of those students who indicated that they were employed answered that Excel was a substantial part of their daily workload. The responses to our surveys and talking with our students indicate that we were successful in achieving these objectives.

This First Summer Session (2021) section of ACT 600, Managerial Accounting, required that the MOS Excel Exam be part of their final grade. In addition, GMetrix (an online study tool that gives the students practice "taking the exam," not just learning the Excel features) was used as part of the student resources for the class. The results from this semester - all 30 registered students passed - and their feedback on the effectiveness of GMetrix guided our decision to promote using GMetrix in the Fall in our undergraduate classes. Instructors will demonstrate the features and benefits of the GMetrix system and show students how to purchase the voucher (\$40) from Certiport. The GMetrix SMS version 7 will be loaded onto PCs in the business school so that students can study either at home or at school. The format used by Nesrin Bakir at West Texas A\&M University also guided our decision to divide the class into a 12-week managerial accounting component and have a 4-week boot camp that will focus on Excel skills and preparation work for the MOS Certification Exam. The boot camp will be first up in the semester so that students can use their new or refreshed Excel skills on Managerial Accounting assignments. Guest speakers from Finance, Management, and Marketing will address the need for Excel skills in non-Accounting positions. Our campus will be fully opened, and instruction will be in-person this Fall. This will allow us to monitor our students' progress much better and to provide interactive help in Excel and Managerial Accounting work in real time. If a student has already earned the Excel Certification, we will offer the advanced Excel Certification as a replacement, or if needed, the MOS certification in Word, Access, PowerPoint and/or Outlook.

This experimental study was conducted to gather information about offering Excel Certification within a required course. Our future decisions about this offering will depend on funding and testing center availability as well as university policies about charges to students. Further research is needed to understand how other CATC colleges and universities administer and price their certification opportunities.

\section{ACKNOWLEDGEMENTS}

We would like to thank the Office of the Provost, the Center for Faculty Excellence, and the Department of Accounting at Cleveland State University for providing funds to support this project.

\section{REFERENCES}

AACSB. (2002). Management Education at Risk. Retrieved from https:/www.aacsb.edu//media/aacsb/publications/research-reports/management-education-at-risk.ashx?la=en 
Bakir, N., Dana, K., \& Abdullat, A. (2019, December). Certifying Business Students in Microsoft Office Specialist Certification Excel Core Exam: Lessons Learned. Information Systems Education Journal, 17(6), 4-11.

Baldwin Wallace ACC 245 Bloomberg \& Excel Certifications (3 credit hour course). (n.d.). Bloomberg and Excel Certifications will allow students to gain certifications in both Excel and Bloomberg Market Concepts while also applying skills through projects and assignments in order to build proficiency. Retrieved from http://catalog.bw.edu/preview course nopop.php?catoid=10\&coid=19975

Baldwin Wallace Microsoft Excel Expert 2019 Certification - Career Training - \$650 including voucher. (n.d.). Retrieved from https://careertraining.ed2go.com/bw/training-programs/microsoft-excel2019-certification-training-voucher-included/

Burning Glass Technologies. (2015). Crunched by the Numbers; The Digital Skills Gap in the Workforce. Retrieved from http://burning-glass.com/research/digital-skills-gap/

Certiport. (2017). Microsoft Office Success Stories. Retrieved from https://certiport.pearsonvue.com/Certifications/Microsoft/MOS/Sucess-stories

Data Pig Technologies. (2013). Periodic Table of Excel Keyboard Shortcuts. Retrieved from https://www.core-ct.state.ct.us/training/pdf/Periodic_Table_Of_Excel_Keyboard_Shortcuts

Elliott, J.A. (n.d.). AACSB, Responding to the Times, AACSB Chairman Report 2020. Retrieved from https://www.AACSB.edu

Excel Certification Survey. (n.d.). Retrieved from www.ziprecuitier.com/salaries/Excel-Expert-Salary

Lambert, J. (2017). MOS 2016 Study Guide Exam 77-727 Microsoft Excel. New York, New York: Pearson Education, Inc.

Lee, L., Shiffiett, E., \& Downen, T. (2019, September). Teaching Excel Shortcuts: A Visualization and Game-based Approach. Journal of Accounting Education, 48, 22-32.

One Education. (2021). 20 Must-have Excel Skills for Professionals in 2021. Retrieved from https://www.oneeducation.org.uk/must-have-excel-skills-for-professionals/

Pathways Commission on Accounting Higher Education. (2012). Charting a National Strategy for the Next Generation of Accountants. American Accounting Association and American Institute of Certified Public Accountants.

Pelzer, J., \& DeLaurell, R. (2018). Implementation of AACSB Standard A7: A Strategy for Limited Resources. The Accounting Educators' Journal, XXVIII, 117-138.

Randall, M.H., \& Zirkle, C.J. (2005), Information Technology Student-based Certification in Formal Education Settings: Who Benefits and What is Needed. Journal of Information Technology Education, 4, 287-306.

Rassuli, A., Bingi, P., Karim, A., \& Chang, O. (2012). A Survey of Critical Knowledge and Skills of Business School Graduates: Employer Perspectives. The Journal of International Management Studies, 7(2), 1-6.

Rebele, J.E., \& St. Pierre, E.K. (2019, July). A Commentary on Learning Objectives for Accounting Education Programs: The importance of Soft Skills and Technical Knowledge. Journal of Accounting Education, 48(2019), 71-79.

Rotondo, G. (2020, June). Closing the Technology Skills Gap in Accounting Education: Making Excel Certification a Student Responsibility. Business Education Innovation Journal, 12(1), 30-37.

Seattle University/Albers School of Business and Economics. (n.d.). Retrieved from https://www.seattleu.edu/business/undergraduate/excel-certification/

Troy University Excel Certification Program. (n.d.). Retrieved from www.certport.com/mos

UNC Bryan School of Business and Economics. (n.d.). Retrieved from https://bryan.uncg.edu/currentstudents/resources/excel-certification/

Wild, J.J., Shaw, K., \& Chiapetta, B. (2019). Financial \& Managerial Accounting Information for Decisions. New York, New York: McGraw Hill Education. 


\section{APPENDIX}

FIGURE 2

BETA ALPHA PSI CREATED INFO GRAPHIC

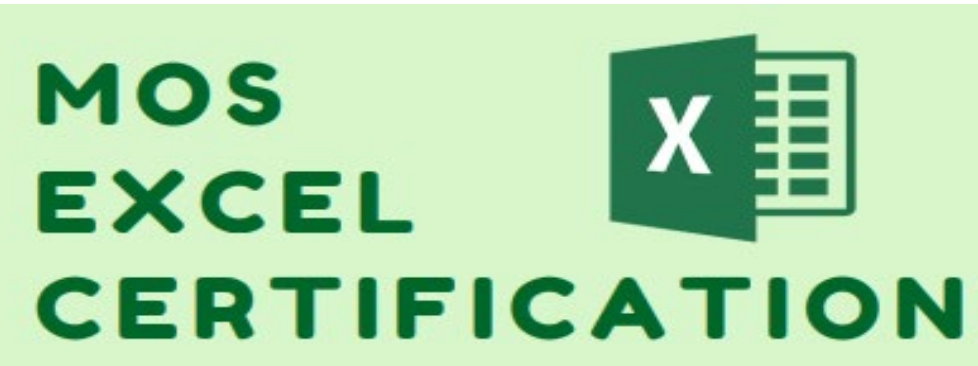

WHAT IS AN EXCEL CERTIFICATE

The MOS Excel certification is the only Microsoft-recognized

foundational Excel certification in the world. It measures a

student's ability to use Microsoft Excel to manage and display data. You can get certified at the specialist and the expert level.

\section{THE CERTIFICATION EXAM}

The exam is fifty minutes long, includes 35 questions using simulated

Excel spreadsheets, and can be taken at CSU or remotely.

\section{EXAM TOPICS COVERED}

SPECIALIST

- Manage Worksheets \& Workbooks

- Manage Data Cells and References

- Manage Tables and Table Data

- Use Formulas and Functions

- Manage Charts

\section{EXPERT}

- Manage Workbook Options

- Apply Custom Formats \& Layouts

- Create Advanced Formulas

- Create Advanced Charts \& Tables

\section{RESOURCES PROVIDED}

If you are interested in taking the MOS specialist or expert Excel certification exam, CSU will provide you with the study guide, practice problems, and video walk-throughs to help you in your journey. The best part - this is no cost to you! Email any questions you may have to registerforexcel@gmail.com.

\section{BENEFITS OF GETTING CERTIFIED NOW}

\footnotetext{
- Certified students make more money

- Excel knowledge is in demand by employers

- Other students recommend learning Excel early
} 
FIGURE 3

MONTE AHUJA COLLEGE OF BUSINESS DECEMBER 2020 NEWSLETTER

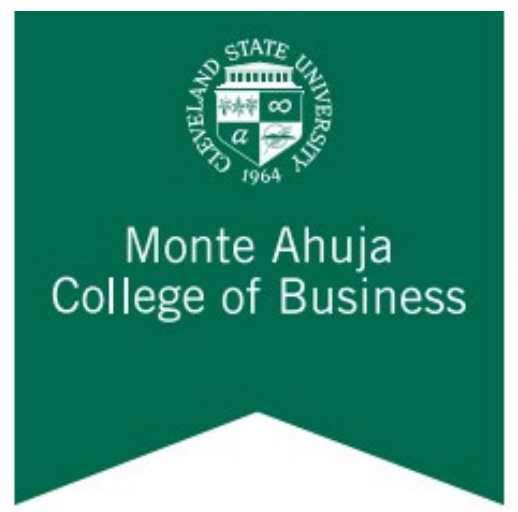

\section{ACCOUNTING STUDENTS:} Sarn MICROSOFT OFFICE SPECIALIST EXCEL certifcation

IN FALL 2020 THE ACCOUNTING DEPARTMENT conducted research on offering Microsoft Office Specialist Excel 2016 certifications to Cleveland State business students. Initial students assisting with research were Eleena Tol, Kaila Griffin and Brice Bechtel.

Our goal is to offer this certification to all ACT 222, Introductory Accounting II (Managerial) students. In addition to the test group, an initial group of 11 students from ACT 222 took and 5 passed the Excel certification exam.

Certiport stated that the the first time pass rate is $20 \%$ and the CSU students in the initial group exceeded that pass rate.

Research indicates that the most requested skills from employers for new graduates are excellent oral and written communications, detail orientation and Microsoft Office proficiency. Accounting graduates must have Excel skills to pass the soonto-be-revised CPA exam.

MOS certification is the leading IT certification in the world. More than 2 million MOS exams are taken every year in over 140 countries. Offering MOS certification as part of the curriculum is a step towards closing "the skills gap". Students are able to leverage learning and instructional materials, preparatory assessment exams and industryrecognized Microsoft certification to ensure future success in today's technology-driven learning and workforce environments.
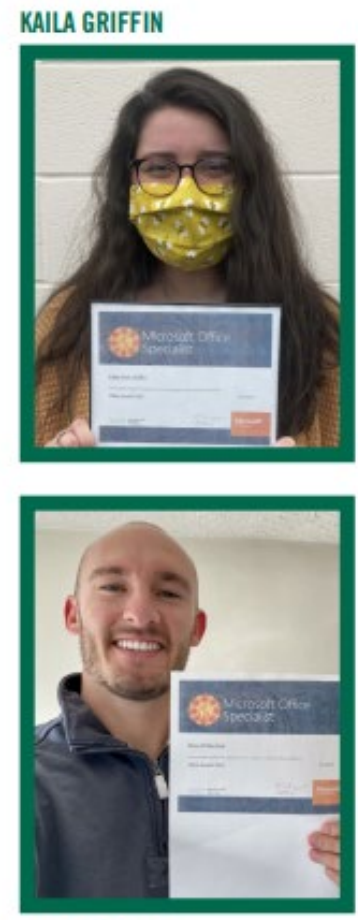

BRICE BECHTEL

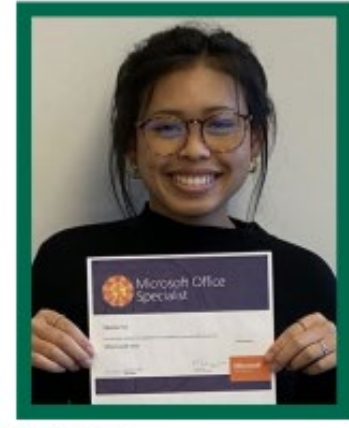

ELEENA TOL.

\section{"Excel certifications enhance your resume so that future employers will recognize your achievements over the "standard" applicant." \\ - From a student who passed the MOS Excel certification}

